\title{
LOUVRE ABU DHABI: SOCIAL MEDIA IN MARKETING CULTURE
}

\author{
Philip Effiom Ephraim*
}

\author{
Higher Colleges of Technology RKWC, United Arab Emirates
}

\begin{abstract}
For almost two decades, The United Arab Emirates (UAE) has been on a mission to boost its culture sector through projects that promote cultural enrichment, openness and tolerance, a move from previously conservative notions. The UAE's interest and commitment to developing its culture sector is anchored on its Cultural Mandate, a document highlighting the country's cultural vision for the next thirty years - the Abu Dhabi Vision 2030 Master plan. This new cultural movement has witnessed the birth of several new museums of which Louvre Abu Dhabi stands out as a museum that celebrates global cultures. In the wake of attractive new media technologies and new online audiences, museums are challenged to market themselves with new technologies in order to be attractive and remain relevant in contemporary society. A mixed analysis of data revealed Louvre Abu Dhabi's strategic use of social media to market its activities as well as promote the UAE. The study observed the use of only four social media including, Twitter, Facebook, YouTube and Instagram. Louvre Abu Dhabi applied the marketing technique of corporate foresight in media selection and strategic messaging through images, questions and creating audience anticipation. This study argues that through social media, Louvre Abu Dhabi is able to market its activities and events and promote the UAE to global audiences online. By providing digital platforms for attracting audiences and gaining feedback, social media helps Louvre Abu Dhabi to fulfill its cultural function of propagating intercultural understanding and tolerance in the UAE.
\end{abstract}

Keywords: Louvre Abu Dhabi, UAE, social media, culture, marketing

\section{Introduction}

Museums are cultural centers that serve educational, research and entertainment functions in society. Museums are becoming increasingly popular in most established cities and towns worldwide (Arinze, 1999). Museums have an interesting history. While developing and spreading quickly in Africa, Europe and parts of Asia, the idea of establishing museums was much slower in the Arabian Gulf. Gulf countries including: Bahrain, Iraq, Kuwait, Oman, Qatar, Saudi Arabia and the United Arab Emirates, were much slower in accepting museum culture. Latham and Simmons (2014) argue that this aversion was due to conservative religious beliefs and resistance to colonialist European museology. Gulf countries were not excited to showcase a 'pagan' past of artifacts that contradicted their strong Islamic beliefs. Also, museology at the time tended to portray history from a colonial perspective in which Arabic culture was inferior to Western culture.

The first Gulf museums appeared between 1960 and 1970. With newfound wealth from crude oil, Gulf countries greatly prospered and embarked on massive projects to develop infrastructure. However, fluctuating and dwindling oil prices changed national focus towards the development of other non-energy sectors of the economy like culture and tourism. Gulf States have strategically been diversifying their economies by translating abundant oil and gas resources in to new areas of institutional infrastructure (Ulrichsen, 2016).

The development of the culture sector has become top priority in the Gulf, leading to the development of new cultural policies in which the establishment and improvement of museums play leading roles both nationally and internationally. These countries were quick to recognize that the establishment of museums empowers both the tourism and educational sectors, providing sites for tourist visits and spaces for learning and research. The region is witnessing an era in which culture, especially the creation of museums, has become an integral part of national policy planning (Bouchenaki, 2013). 
The UAE for example, has a strong focus on culture and tourism. The UAE's interest and commitment to developing its culture sector is anchored on its Cultural Mandate, a document highlighting the country's cultural vision for the next thirty years - the Abu Dhabi Vision 2030 Master plan. The Cultural Mandate was developed by the Ministry of Culture and Tourism, Abu Dhabi and outlines various policies and plans for promoting UAE's cultural and historical heritage. In regards to the development and management of museums, the Cultural Mandate states that:

"Our responsibility to promote the dynamic culture of our emirate extends to overseeing the development of the Abu Dhabi's future museums on Saadiyat Island, including Louvre Abu Dhabi, Zayed National andeum Guggenheim Abu Dhabi”. (https://tcaabudhabi.ae/en/what.we.do/culture.aspx)

UAE's cultural policy has led to establishment of several contemporary museums including Guggenheim Abu Dhabi and Louvre Abu Dhabi. Both museums are part of UAE's ambitious Saadiyat Island Project, to create a cluster of museums and cultural centers to attract art lovers and tourists worldwide.

However, some scholars have criticized these new museums as being merely publicity stunts and not really for the preservation and promotion of national identity and culture. Al Qassemi (2016) describes these new museums as 'visibility museums' different from traditional heritage museums. The main aim of these ambitious new museums, designed by celebrity architects, is to enhance UAE's international portfolio and transform it in to a cultural hub to rival France and the USA (Ajana, 2015).

\section{UAE Changing Socio Cultural Landscapes}

Founded in December 1971, the UAE could be described as a young country at the cross roads of conservatism and openness. Many families still cling to traditional Arabic and strict Islamic moral codes (Mazrouei and Pech, 2015). Conservatism is reflected in dress codes, gender associations and aspects of social life. There exist strict laws that prohibit dissent against the country's leadership. However, these laws do not apply to foreigners in many contexts. Foreigners are expected to show respect for Emirati people and culture.

With a total population of 9.4 million made up of almost entirely expats as compared to a small number of local Emiratis, UAE's leadership were quick to recognize the need for new policies to foster peace and cultural harmony among its culturally diverse population of over 180 different nationalities. A recent example was the declaration of 2019 as the Year of Tolerance. The invitation and visit of Pope Francis in February 2019 was in line with UAE's goal to further interfaith and intercultural dialogue between Muslim and Christian groups.

UAE's new cultural movement could be understood as its growing acceptance of change in an increasingly culturally globalized world. Cultural globalization refers to cross border flows and exchanges of national and international cultures (Crane, 2011). Cultural globalization takes place within and among countries and has gone on for centuries as people travel abroad or come in contact with new cultures from which they borrow aspects to improve their home cultures (Pieterse, 2009).

Scholars have pointed to new media as key drivers of cultural globalization alongside other factors like increasing travel and tourism. The globalized age has birthed new and active online communities (Ephraim, 2010). Social media provides spaces for intercultural exchange between highly diverse users from round the world. Social media thus promotes intercultural relations online that sometimes translate in real time interactions. Museums as cultural institutions more than ever, need to incorporate social media in their daily operations to reach out to new audiences who are virtually always online.

\section{Museums, Communication Planning and New Media}

Communication plans are essential for the smooth running of organizations whether business or non-profit. Communication planning involves five key components: audience analysis, communication objectives, channel 
selection, responsibilities and timing. Communication planning is particularly important for communicating change (Newman, 2016).

Good communication planning helps organizations to achieve corporate goals. There can be no effective management or work coordination without communication. With the emergence and proliferation of social media, interpersonal, socio-economic and socio-cultural exchanges have been taken to a whole new level. Daily operations in financial, educational, arts and culture industries have become quicker, more accessible and interactive. Social media communication acts such as: posting, liking, tweeting, sharing, commenting and replies, are increasingly replacing more older channels like letters, emails and responses to queries on websites (Ephraim, 2013).

Social media has produced new online communities. These tech-loving communities are often very demanding. Online audiences often demand explanations of issues and solutions to problems in quick, clear, objective and simple formats. Via social media, online communities can also mobilize together to campaign in support or against organizations with the resultant effects going viral within days (Ephraim, 2010). This shift has impacted the management of museums creating new opportunities and challenges. Through social media, museums can network with other museums and connect to their audience. Museums that were once far away now share their collections virtually to global audiences online via websites and social media (Latham and Simmons, 2014). Museums are beginning to use social media to reach wider audiences by building interactive environments to foster better public engagement through discussion (Marakos, 2014).

As a contemporary museum designed to celebrate global cultures, Louvre Abu Dhabi actively uses social media among other new digital technologies like VR headsets, and interactive swipe screens. These new technologies are especially intended to capture and sustain the interests of teenagers and children. Their intention could be understood as a way of trying to make museums cool (Al Qassemi, 2016). Museums now face the challenge of competing to win the attention of audiences online and in real time. It is therefor necessary to study how Louvre Abu Dhabi employs social media in planning its marketing communications.

\section{A Museum of Global Cultures - Louvre Abu Dhabi}

Louvre Abu Dhabi was planned and designed as a contemporary museum to celebrate all global cultures in line with the UAE's Cultural Mandate to:

"inspire professionals and enthusiasts in arts, literature and music locally and internationally, we
also work to preserve traditional artistic practices and handicrafts"
(https://tcaabudhabi.ae/en/what.we.do/culture.aspx)

The famous French architect Jean Nouvel designed Louvre Abu Dhabi. The 26,000 square foot structure located on Saadiyat Island is particularly noted for its intricate metallic roof that resembles a flying saucer. The illusion created is of a metallic building floating on a lake (see Figure 1). Officially opened on November 8, 2017, Louvre Abu Dhabi represents one of the best reflections of government commitment to promoting cultural understanding and tolerance for other global cultures. The idea for the museum came through a bilateral agreement signed between the UAE and France in March 2007. The thirty-year agreement allows for the use of Louvre Paris' Franchise in Abu Dhabi at the cost of $\$ 520$ million including loans of art works, special exhibitions and managerial advice to the tune of $\$ 747$ million. 


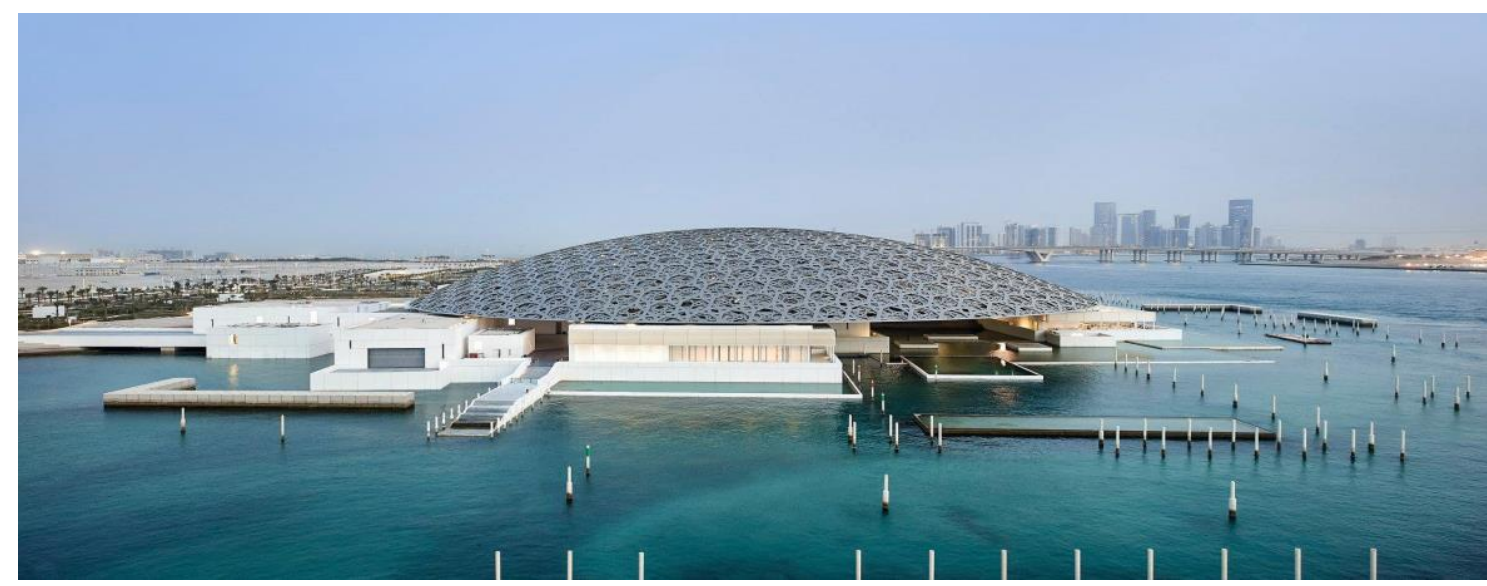

Figure 1: Ariel view of Louvre Abu Dhabi

\section{Source: https://www.facebook.com/LouvreAbuDhabi/}

Louvre Abu Dhabi describes itself as a universal museum on a mission to create human connections through art, dating from prehistory to the present. The museum seeks to broaden the appeal for global cultures among Emiratis, resident expatriate communities and international tourists and beyond. The museum's twelve galleries showcase collections from the earliest human civilizations to the contemporary period.

The project has been critiqued as being UAE's means of trying to exploit already established global brands instead of focusing on building its own (Kluijver, 2014). Others have pointed out to the lack of potential for Louvre Abu Dhabi to promote Emirati culture. Some critics also point to issues of cultural sensitivity of some of the ancient artifacts that contradict Islamic beliefs. The exploitation of construction workers involved in the project is not left out in critical commentary (Ajana, 2015).

\section{Research Question}

Marakos (2014) argues that there is not significant amount of research providing insights in to how museums employ social media within different cultural contexts. In view of the above, the research question below was drawn up to guide this study:

1. How does Louvre Abu Dhabi employ social media to market its cultural activities online?

\section{Method and Data}

In order to answer the above question, the study employed a mixed approach to social media data (Andreotta et al 2019). Both numerical and qualitative textual data were collected and analyzed from all Louvre Abu Dhabi's social media accounts. Quantitative data was extracted using the various platform analytics features. Volume analysis was employed. Volume analysis represents the simplest approach to social media data and focuses on numerical data such as number of platform users and their actions within a certain demographic over a specific time frame (UK Government Social Research, 2016).

A total of 1000 posts were viewed and read to gain qualitative insights into content posted, users' comments and replies. Table 1 shows a data summary of all Louvre Abu Dhabi's social media channels. The table groups data according to: social media platform, join date, number of posts/tweets/videos, followers/subscribers, following, likes and views. Missing details from the table represent data that was not publicly accessible to the researcher due to privacy and page administration factors. 
Table 1 :Louvre Abu Dhabi - Social Media Reach and Engagement

\begin{tabular}{c|c|c|c|c|c|c}
$\begin{array}{c}\text { Social } \\
\text { Media } \\
\text { Platform }\end{array}$ & Join Date & $\begin{array}{c}\text { Tweets, } \\
\text { Posts, } \\
\text { Videos }\end{array}$ & $\begin{array}{c}\text { Followers, } \\
\text { Subscribers }\end{array}$ & Following & Likes & Views \\
\hline Facebook & $10 / 2014$ & - & 153,148 & - & 150,160 & - \\
\hline Twitter & $09 / 2014$ & 2,494 & 44,700 & 71 & 2,472 & - \\
\hline Instagram & $10 / 2014$ & 700 & 95,600 & 22 & - & - \\
\hline YouTube & $10 / 2014$ & 32 & 7,783 & - & - & $1,787,286$
\end{tabular}

\section{Results}

Analysis of Louvre Abu Dhabi's social media yielded the following results:

\section{Channels and Audience}

Analysis revealed the use of only four social media channels: Facebook, Twitter, Instagram and YouTube as indicated on the museum's official website. The four channels were studied over a four-month period (from September to December 2018) guided by the hash tag \#LouvreAbuDhabi. All accounts were verified as authentic, all having the blue check mark. Table 1 shows an interesting variety in number of followers and subscribers. Louvre Abu Dhabi's highest following and number of likes was on Facebook (153, 148 and 150,160 respectively). Closely following Facebook was Instagram with 95,600 followers and Twitter with 44,700 followers. The least number of subscribers was YouTube with 7,783. Although having the least number of subscribers, YouTube had the highest number of views $(1,787,286)$ compared to other channels. It therefore could be understood that Facebook, Instagram and Twitter are Louvre Abu Dhabi's key social engagement channels, as they attracted the highest audience following not just mere views as in the case of YouTube.

\section{Strategic Corporate Foresight in Channel Selection}

Table 1 also revealed the join dates to each social media platform. Louvre Abu Dhabi opened its social media accounts between September and October 2014. By deliberately opening social media accounts and engaging audiences at the time, (three years before its official opening in November 2017) Louvre Abu Dhabi could be said to have applied the marketing strategy of corporate foresight. Corporate foresight seeks to understand the possible futures of organizations (Alsan and Oner, 2003). It is a technique that is applied in uncertain environments, where organizations are not completely sure of public reception towards their products or services. Located in a culturally conservative environment, Louvre Abu Dhabi employed wise decision-making by deciding to test audience reception before its eventual opening. Corporate foresight is particularly useful in communication planning to help organizations collect audience demographic data and gauge engagement through numbers of positive/negative comments, likes and shares.

\section{Strategic Messaging - Images, Questions and Audience Anticipation}

Qualitative analysis of posts revealed Louvre Abu Dhabi's use of three engagement tactics: posting images, posing questions and creating audience anticipation. In order to attract attention and expand reach, Louvre Abu Dhabi posted several interesting images including; photos of external views of the museum, artifacts, special exhibitions and text announcing events and special discount offers. Questions were also posed to elicit response form users. Questions mostly bothered on the identification of particular artifacts. Examples of questions posed included: "can you guess which animals are represented in these artworks?" "would you dare to face the sphinx as he is the keeper of the third gallery?" "where do you think this casket decorated with animals scenes comes from?" Louvre Abu Dhabi's use of questions could be understood as a way of promoting dialogue on various 
artifacts drawn from different cultures and as a way of increasing audience engagement. By engaging with other cultures, audiences gain more understanding and tolerance.

The study also observed the use of audience anticipation in message content. Audience anticipation is a marketing strategy that gives organizations a unique comparative advantage as it keeps audiences waiting for the introduction of particular products or services (Kandampully and Duddy, 1999). The use of audience anticipation was particularly evident on a tweet announcing the acquisition of Leonardo Da Vinci's famous painting, Salvator Mundi. The Salvator Mundi tweet was posted on December 6, 2017 and is entitled Da Vinci's Salvator Mundi is coming to \#LouvreAbuDhabi. The tweet attracted 1088 likes, 909 retweets and 56 comments (see Figure 2). Louvre Abu Dhabi's delay tactics could be understood as its marketing strategy to create and sustain audience's attention to its products.

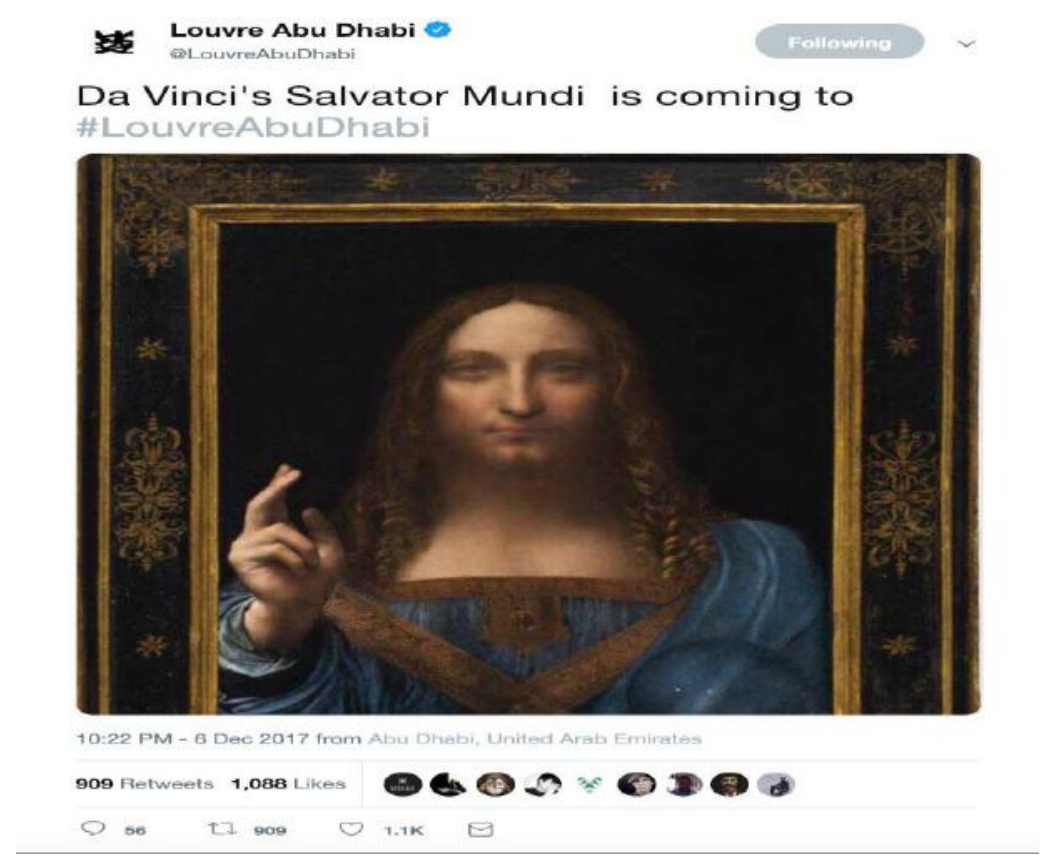

Figure 2: Screenshot Showing Tweet Announcing Salvator Mundi

Comments included a mix of commendations, anticipatory questions and critical commentary (see Figure 3). Select examples of commendations include: "wonderful!!! congratulations to Louvre Abu Dhabi”, "very good the Salvator Mundi will soon be on public display in the museum", “can't wait", "Congrats! Can't wait to see it".

Anticipatory questions included: "when, when, when", "a few questions: when will it be on view, Will it be staying there or is it a short term loan? Do you own it? Critical comments included: "Hope it was really painted by Leonardo", "freaky spawn of Jesus and Mona Lisa" "shame on you...you spend money to please your masters", "Louvre ain't what it used to be", among several others. 


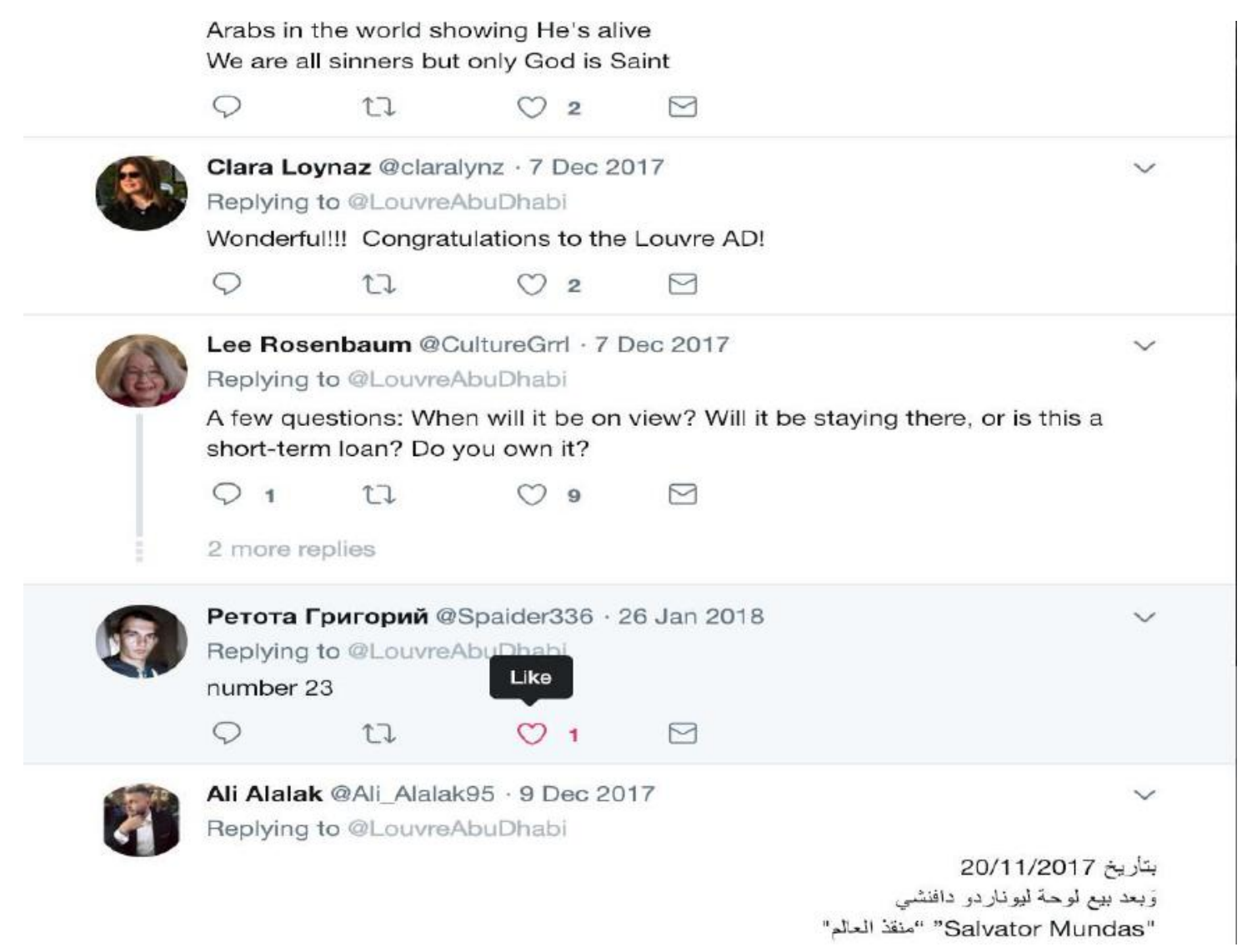

Figure 3: Screenshot showing a cross section of Twitter comments

\section{Closing Discussion}

Change is not an easy process within any organization. Cultural change within a society is even more challenging to achieve as familiarity with the old mindset and fear of the new unknown, often leads to resistance from the population. Governments often rely on cultural institutions like museums, religious and educational insitutions to help push new socio-cultural ideas. Museums play a key role in reflecting cultural change and inclusion within societies (Sandell, 2007). By using new media resources like social media, museums are able to reach audiences online with their messages. In a country on a serious mission to becoming a leading global cultural melting pot and technological hub, Louvre Abu Dhabi plays a critical role in spreading UAE's cultural Vision 2030.

The value of social media in disseminating UAE's cultural vision of intercultural understanding cannot be over stressed. The use of social media as a key channel, demonstrates Louvre Abu Dhabi's recognition of the importance of channel selection and audience analysis. The museum recognized that its target audience is mostly online especially on social media. The people of UAE have taken to social media as fish to water. Social media is increasingly giving voice to the voiceless and serving as a hub for new cultural ideas (Global Media Insights, 2018). By attracting local and international audiences social media provides Louvre Abu Dhabi and consequently the UAE more international visibility. These online engagements often translate to real time visits 
to the museum as evident from testimonies in the comment sections of each social media platform, a development good for both business and tourism.

Louvre Abu Dhabi thus effectively functions well in its role as a museum of visibility by drawing the needed international visibility to UAE (Al Qassemi, 2016). Visitors both resident and international, flock to visit the museum to appreciate its multicultural holdings. Beyond just visibility, Louvre Abu Dhabi has been successful in promoting wider acceptance for international arts and culture both within the UAE and the Gulf. $47 \%$ of Louvre Abu Dhabi's staff is local, evident of increasing Emirati interest and acceptance in working with other cultures (Gulf News, 2018).

So far, Louvre Abu Dhabi's social media journey has been very successful as evident with a growing reach of almost 2 million. The growing audience size and engagement reflects the museum's growing international appeal and success in fulfilling UAE's goal of fostering intercultural understanding and tolerance.

\section{Limitations and Suggestions for Further Research}

Social media research is increasingly gaining interest within media and communication research. Scholars are increasingly interested in exploring the various ways in which social media is employed in political, business and cultural sectors. This paper made a modest attempt to explore how a UAE based global museum uses social media to market its activities and promote the country's cultural sector. Although interesting findings were made, the study was however limited in both quantitative and qualitative aspects.

Quantitatively, not all social media data was available for analysis. The study could not ascertain the number of Facebook posts, following and views due to privacy limitations. Details on number of YouTube followers and likes were also missing. It will be good for future studies to directly contact the management of Louvre Abu Dhabi for more insights about their use of Facebook and YouTube. Qualitatively, more detailed content and critical discourse analysis is needed to further explore users' comments and organization responses. It will be good to study how political and cultural power is reinforced and challenged in various posts and replies online.

\section{References}

Andreotta, R. et al 2019 Analyzing Social Media Data: A Mixed methods Framework Combining Computational and Qualitative Text Analysis, Behavior Research Methods 52 (1) 1 - 16

1 Million Visitors to Louvre Abu Dhabi, Gulf News Date of Access: 10/03/2019 https:/gulfnews.com/uae/1 million-visitors-to-louvre-abu-dhabi-1.1541829895411

Alsan, A. and Oner, M. 2003 An Integrated View of Foresight: Integrated Foresight Management Model, Foresight 5 (2) 33 - 45

Arinze, E. 1999 The Role of the Museum in Society. Museums, Peace, Governance and Democracy in the 21st Century', Public Lecture: Georgetown, Guyana

Bouchenaki, M. 2013 The Extraordinary Development of Museums in the Gulf States, Museum International 63 (3) 93-103

Ephraim, P. 2013 African Youths and the Dangers of Social Networking: A Culture-centered Approach to Using Social Media, Ethics and Information Technology 15 (4) 275 - 284

Ephraim, P. (2010) Adopting Multimedia Systems in Public Relations: Some Imperatives for Nigeria, African

Council for Communication Education Conference Date of Access: 10/03/2019 https://www.academia.edu/24124533/Adopting_Multmedia_Systems_and_Applications_in_Di

gital_Public_Relations_Some_Imperatives_for_Nigeria

UAE Social Media Statistics (2018) https://www.globalmediainsight.com/blog/uae-social-media-statistics/ Date of Access: 10/03/2019

James, P. and Steger, M. 2010 Globalization and Culture Vol. 4 Ideologies of Globalization. (SAGE) 
Kandampully, J. and Duddy, R. 1999 Competitive Advantage through Anticipation, Innovation and Relationships, Management Decision 3 (1) 51 - 56

Kelly, L. 2006 Measuring the impact of museums on their communities: The role of the 21 st century museum. Proceedings of INTERCOMM 2006

Kluijver, R. 2014 Contemporary Art in the Gulf: Context and Perspectives Date of Access: 12/03/2019 https://issuu.com/robertk1/docs/contemporary_art_in_the_gulf_for_pr

Latham, K. and Simmons, J. 2014 Foundations of museum Studies: Evolving Systems of Knowledge. (California: ABC-CLIO-LLC)

Marakos, P. 2014 Museums and Social Media: Modern Methods of Reaching Wider Audience, Mediterranean Archeology and Archaeometry, 14 (4) 75 - 81

Mazrouei, H. and Pech, R. 2015 Working in the UAE: Expat Management Experiences, International Journal of Business Tourism and Applied Sciences 3 (1) $19-28$

Newman 2016 Communication Planning: A template for Organizational Change. Cornell Hospitality Report 16 (3) 3 - 6

Pieterse, J. 2009 Globalization and Culture. (Maryland: Rowan and Littlefield)

Sandell, R. 2007 Museums as Agents of Social Inclusion, Museum Management and Curatorship, 17 (4) 401 418

Quassemi, S. A. 2016 The Gulf States National Museums, Gulf Affairs, Autumn 2016 30-31 https://www.oxgaps.org/files/commentary_al_qassemi.pdf

Ulrichsen, K. (2016) The Gulf States in International Policy. (Basingstoke: Palgrave-Macmillan)

Using Social Media for Social Research: An Introduction, Social Media Research Group, UK Date of Access: 10/03/2019 https://assets.publishing.service.gov.uk/government/uploads/system/uploads/attachment_dat a/file/524750/GSR_Social_Media_Research_Guidance_-

_Using_social_media_for_social_research.pdf 